\title{
Oligarquización y extractivismo. Cerrojos a la democratización de la política ambiental en Chile
}

\author{
Alejandro Pelfini, ${ }^{*}$ Rodrigo Mena**
}

Perfiles Latinoamericanos
FLACso México

\section{Resumen}

El objetivo de este artículo es demostrar que la modernización de la institucionalidad ambiental en Chile (la Nueva Institucionalidad Ambiental introducida en 2009/2010) termina consolidando las redes informales que han conectado tradicionalmente a sus principales actores: inversores, Estado y expertos. En consecuencia, se trata de una política pública que a pesar de introducir estándares de gobernanza signados por la accountability, transparencia y participación ciudadana no contribuye a la formación de ciudadanía y agenda pública en torno a modelos de desarrollo y de uso de recursos naturales, sino que se limita a evaluar/paliar/legitimar agendas preconstituidas, como lo son generalmente los proyectos de inversión productiva, extractiva o de infraestructura. Esto se debe, a nuestro juicio, a que la tendencia a la oligarquización propia del sistema político chileno y de la dominación de sus élites en general, así como la perduración de un modelo de acumulación basado en el extractivismo de recursos naturales sirven como cerrojo estructural a cualquier modificación de fondo de la política ambiental en una dirección más democrática.

\begin{abstract}
The aim of this article is to show that the modernization of Chile's environmental institutions (called Nueva Institucionalidad Ambiental, introduced in 2009/2010) consolidates the informal networks that have traditionally linked its main actors (investors, State and experts). Consequently, it is a public policy that despite the incorporation of governance standards marked by accountability, transparency and public participation does not contribute to the formation of citizenship and public agenda around models of development and use of natural resources, but limited to assess/ mitigate/legitimize pre-established agendas, introduced by productive, extractive or infrastructure investment projects. In our view, this is due to the tendency to oligarchization of the Chilean political system and of the domination of elites in general and the persistence of an accumulation model based on the extraction of natural resources. Both serve as a structural lock that bolts any substantive change of environmental policy in a more democratic direction.
\end{abstract}

Palabras clave: nueva institucionalidad ambiental, gobernanza privada, accountability, transparencia, participación ciudadana.

Keywords: New environmental institutional framework, private governance, accountability, transparency, public participation.

* Doctor en Sociología por la Albert-Ludwigs-UniversitätFreiburg (Alemania). Académico en el Departamento de Sociología de la Universidad Alberto Hurtado (Chile). Director del Módulo Latinoamericano del Global Studies Programme, Flacso Argentina.

** Magister en Medioambiente por la Universidad de Melbourne (Australia). Académico de la Universidad Central de Chile (La Serena, Chile). 


\section{Introducción}

hile, como uno de los primeros y relativamente exitosos experimentos neoliberales en el mundo (Valdivia, 2001; Bravo, 2012), aparece como un laboratorio de modernización ecológica en contextos semiperiféricos. ${ }^{1}$ Asimismo, su reciente política ambiental fue reformada en el año 2009 con la llamada Nueva Institucionalidad Ambiental (NIA) que comienza a implementarse al siguiente año y que le otorga una mayor jerarquía a la política ambiental dentro de la administración pública (Barton et al., 2007; BCN, 2010a, 2010b; Boettiger, 2010). Esta reforma, junto con la creación de más instituciones de fiscalización y de tribunales específicos, introdujo exigencias de accountability, transparencia y participación en fases específicas del proceso de políticas públicas (BCN, 2010a, 2010b; CONAMA, 2010). En principio se esperaba alcanzar mayor transparencia y accountability (rendición de cuentas) horizontal en la diferenciación de funciones entre tribunales ambientales, el Servicio de Evaluación Ambiental (seiA), la Superintendencia y el Ministerio, en vez de haberlos puesto bajo un solo gran ministerio (Boettiger, 2010).

Si bien este cambio supone un diseño institucional nuevo, es importante observar que dichas estructuras no aparecen en una tabula rasa sino que deben dar continuidad a una política previa - aun cuando débil e incipiente-e insertarse en una trama de actores y relaciones ya establecidas, marco que la constriñe con fuerza. En este escenario es imprescindible preguntarse por las continuidades y rupturas de esa reforma, así como por los actores centrales que la protagonizan, dado que con lo anterior se dio la paradoja de que la introducción de mecanismos más formales, transparentes y participativos de gestión parece afianzar las redes informales a nivel intraélite, mientras que la sociedad civil y el ciudadano de a pie quedan relegados al papel de meros observadores.

Por lo tanto, el objetivo de este artículo es mostrar cómo la modernización de la institucionalidad ambiental en Chile en realidad consolida las redes informales oligárquicas que han conectado tradicionalmente a sus principales actores: inversores, Estado y expertos. La justificación de preguntarse por cómo estas reformas no alteran las estructuras y redes informales tradicionales y el porqué de la necesidad de hacerlo, se basa en que la tesis central de todo el proceso de modernización del Estado, incluyendo sus reformas de segunda

1 Por "contextos semiperiféricos" se entiende a aquellos países con modelos económicos periféricos con capacidad industrial (Hurtado, 2012). Por ende y dada su capacidad productivista, estos países semiperiféricos suelen ser considerados en vías de desarrollo o las clases medias de una estructura social global, como se representa en la teoría "sistema-mundo" (Wallerstein, 1976; Terlouw, 2003). 
generación ${ }^{2}$ y una mayor democratización (incorporando exigencias de mayor accountability, transparencia y participación), se realiza con pretensiones de dar mayor atención política y pretensiones públicas a la cuestión ambiental chilena. No obstante lo señalado, y como hipótesis inicial, se puede decir que estas reformas de segunda generación no alteran la tendencia a la glorificación de la gobernanza privada de los bienes públicos ambientales, ${ }^{3}$ ni la rigidez oculta de los mecanismos no convencionales y los diseños institucionales supuestamente "flexibles".

\section{Historia y fases de la política ambiental en Chile}

Para comprender las reformas de la política ambiental chilena y su incapacidad de modificar los vínculos y redes informales tradicionales, es necesario conocer la historia de lo ambiental en Chile, la cual —a grandes rasgos - contiene dos fases: una legislativa enfocada en el desarrollo de leyes ambientales y construcción de las primeras instituciones de gestión ambiental; y la que corresponde a una modernización con énfasis en el desarrollo institucional, y que culmina con la formación de un Ministerio del Medio Ambiente (Del Fávero \& Katz, 2001).

En la primera fase, el Estado chileno abordó la cuestión ambiental hasta la década de los ochenta, a pesar de y sin hacer eco de que la apertura comercial a los mercados internacionales en la década de los setenta conllevara a que las industrias exportadoras de recursos naturales debían acogerse a las demandas legales que imponían los mercados extranjeros (Rojas, Sabatini \& Sepúlveda, 2003). Respecto a la legislación chilena sobre lo ambiental, la primera referencia se encuentra en el artículo 19 de la Constitución de 1980 (dictada bajo el Régimen Militar), que determina el derecho de las personas a vivir en un medio ambiente

2 Es común que las reformas del Estado en Latinoamérica sean clasificadas como de primera y segunda generación. Las primeras atienden los cambios cuyo fin es lograr un crecimiento económico y en su mayoría se desarrollan enmarcadas por el Consenso de Washington. Por su parte, las de segunda generación se refieren a las transformaciones que buscan modernizar el aparato estatal, específicamente en lo institucional y político.

3 Se entiende aquí "gobernanza privada" (private governance) como la política pública hecha fundamentalmente por agentes privados, o bien liderada y orientada por los criterios de estos. Y se diferencia de la mera participación de agentes privados en el mercado, las prácticas de lobby o la privatización de agencias y programas de la administración pública. También se diferencia de la gestión gerencial (Estado/mercado) y de la gestión asociada (Estado/sociedad civil), ya que en estas el Estado se mantiene como agente principal, en cambio, en la gobernanza privada el Estado se desdibuja (Rudder, 2007). 
libre de contaminación. ${ }^{4}$ Según algunos autores, es posible que la incorporación de este derecho se haya debido a la presión que las ONG ambientales ejercieron sobre el Estado chileno en dos temáticas: la contaminación de Santiago (capital y principal ciudad de Chile) y el retorno de la democracia (Rojas et al., 2003; Rivera, 2011). Desde entonces la cuestión ambiental dejó de tratarse significativamente hasta que, en los noventa, se promulga la Ley 19.300 relativa a las Bases Generales del Medio Ambiente, ${ }^{5}$ y que se crea en el contexto de la Conferencia de las Naciones Unidas sobre el Medio Ambiente y el Desarrollo de Río de Janeiro, celebrada en 1992 (BCN, 1994). Dicha ley surge para regular, entre otros aspectos, los instrumentos de gestión ambiental, entre los que destacaban la creación de una secretaría de Estado para la gestión pública del medio ambiente, la herramienta de gestión "Evaluación Ambiental Estratégica” y el Sistema de Evaluación de Impacto Ambiental (Aylwin, 1992; Hervé, 2010). De igual modo, en 1994 se crea la ConAma (Comisión Nacional de Medio Ambiente), dependiente de la Secretaría General de la Presidencia, entidad que coordina la gestión ambiental del Estado entre los distintos ministerios y programas que implementan políticas relevantes en términos ambientales; sin embargo y por su condición, con escaso peso ejecutivo y sin poder crear una agenda propia (BCN, 1994).

Para comprender el surgimiento de la Ley 19.300 es relevante señalar que durante los ochenta y los primero años noventa el país vio cómo dos proyectos de inversión de gran envergadura fueron identificados como conflictivos por parte de múltiples agrupaciones civiles locales e internacionales. Nos referimos a la construcción de la represas Pangue y Ralco, en el sector del alto del río Biobío, en la viII y IX regiones, con motivo de instalar centrales hidroeléctricas. Ese proyecto había nacido en 1980 desde la Compañía Nacional de Electricidad (Endesa) y se perfilaba como el más importante sistema de producción de electricidad que atendería al 93\% de la población (Soria, 2001). Sin embargo, diversas comunidades locales y pueblos indígenas (mapuches y pehuenches) vieron que sus tierras y medios de vida se afectarían por los proyectos, lo cual generó una serie de manifestaciones públicas, atención internacional y movilizaciones que terminaron con demandas judiciales (Robinson, 1992; Rojas et al., 2003). Como resultado, el proyecto original tuvo que ser modificado y se sentaba un precedente de comunidades locales y organismos civiles activando

4 Y continúa: "Es deber del Estado velar para que este derecho no sea afectado y tutelar la preservación de la naturaleza. La ley podrá establecer restricciones específicas al ejercicio de determinados derechos o libertades para proteger el medio ambiente" (Gobierno de Chile, 1980: Artículo 19).

5 Publicada en el Diario Oficial el 9 de marzo de 1994 y una última modificación: Ley No20.417, MINSEGPRES, del 26 de enero de 2010. 
conflictos ambientales asociados a grandes proyectos de inversión (Robinson, 1992; Soria, 2001; Rojas et al., 2003).

A nivel de gestión y regulación ambiental, con la Ley 19.300 se determinó que todo proyecto de magnitud a nivel nacional solo podría ejecutarse o modificarse previa evaluación de su impacto ambiental (EIA), para lo que no bastaría presentar una declaración de impacto ambiental unilateral. Sin embargo, este Sistema de Evaluación Ambiental comenzó a operar obligatoriamente hasta 1997/1998, de tal modo que durante gran parte de la década de los noventa esto se manejó como un reglamento voluntario (Rojas et al., 2003). Junto a esto, y más allá de los tecnicismos y adentrándonos en el espíritu de la legislación, la Ley 19.300 introdujo una novedad que varios autores (Olivares, 2010; Campos \& Larenas, 2012) han catalogado como clave en la despolitización de la política ambiental desde los ańos noventa en Chile: "La pérdida del derecho ciudadano de exigir el respeto de la garantía constitucional de vivir en un medioambiente libre de contaminación, en donde los derechos constitucionales pasaron a ser objetivos deseables y no demandables, perdiéndose de este modo la relevancia de la mediación de la Corte Suprema en el conflicto medioambiental" (Campos \& Larenas, 2012: p. 47).

A esta transición de lo exigible a lo deseable se le agrega el pasaje de un derecho demandable al Estado a un deber al que es obligado que contribuya cada ciudadano, individualizando y difuminando al mismo tiempo las responsabilidades públicas en cuanto a la calidad del ambiente y al cuidado de un entorno crecientemente vulnerable: "Aquí no se trata de incrementar el catálogo de derechos que el hombre puede exigir al Estado y al resto de los habitantes del planeta. Por el contrario, el respeto y protección del entorno ecológico demanda del ser humano un actuar consonante con la mantención de la armonía natural." (Campos \& Larenas, 2012: p. 47).

En dicho sentido, la política ambiental no cumplía con la función de velar por la reproducción de ecosistemas y de vigilar las actividades productivas de acuerdo al imperativo de la sustentabilidad tanto de los recursos como del entorno natural (Carruthers, 2001). Así, la política ambiental se subordinaba a un objetivo económico-social prioritario: el pleno desarrollo de un país con profundas desigualdades que requiere supuestamente de un crecimiento económico acelerado y sostenido basado en la explotación de recursos naturales (Rojas et al., 2003; Larraín, 2006; Rivera, 2011; Pelfini, 2013). Tal como lo presenta con claridad Estenssoro (2009):

Frente al debate ambiental que se producirá bajo este escenario, los gobiernos concertacionistas, señalando que el dilema entre desarrollo o protección del Medio Ambiente era un dilema falso, se posicionaron en una postura de centro que en- 
fatizaba la reforma gradual del sistema político-económico, con relación a dos polos extremos, como serían el polo neoliberal y el polo ecologista o ambientalista. (Estenssoro, 2009: p. 200).

En relación a las políticas públicas ambientales en Chile, y como argumentan Navarro \& Rivera (2013), producto del modelo neoliberal introducido en la década de los ochenta y la apertura de los mercados al comercio internacional, en Chile se instauró un proceso de desarrollo de políticas extractivas que conllevan la generación de instituciones y políticas que promueven el uso económico de los territorios. De este modo, se refuerza la noción de que el uso de los territorios y la problemática ambiental quedan supeditados al ideario del "progreso" y el "desarrollo", siempre basados en la extracción de recursos naturales destinados a mercados externos (Escobar, 1999; Navarro \& Rivera, 2013).

Reafirmando lo ya mencionado, a cuatro años de la promulgación de la Ley 19.300, en 1998 se publica el primer y único documento que es reconocido como una manifestación explícita de la política ambiental de Chile: "Una Política Ambiental para el Desarrollo sustentable" (COnAma, 1998). Confirmando lo dicho, este documento establece la subordinación de la temática ambiental al modelo de desarrollo del país y fortalece la responsabilidad pública de la gestión ambiental — centrada en el individuo y el colectivo-, pero difusamente en el Estado (CApp, 2013). Un buen ejemplo de lo anterior es el comienzo de la obligatoriedad del Sistema de Evaluación Ambiental en 1997 (Rojas et al., 2003; Espinoza, 2007).

Para muchos (Larraín, 2006; Barton et al., 2007; Navarro \& Rivera, 2013; Pelfini, 2013) es evidente que ese desarrollo de la política ambiental en Chile tiene un origen más exógeno que endógeno, toda vez que se ha impulsado desde el extranjero, sobre todo desde la escala global: sus "portadores" han sido habitualmente compañías internacionales que han introducido en Chile los estándares ambientales vigentes en sus países de origen; las organizaciones internacionales que supervisan la conservación de bienes públicos globales, y los mercados de exportación de Chile con sus propias regulaciones comerciales y de consumo (Navarro \& Rivera, 2013). Con voluntad o no, el gobierno chileno se vio crecientemente obligado a cumplir con tales requisitos y, en cierto modo, las empresas exportadoras también, en la medida en que los consumidores de sus productos o sus accionistas lo exigen — por ejemplo, tras la crisis del virus ISA, en la industria salmonera- (véanse, Barton \& Floysand, 2010; CAPP, 2010; Carreño, 2010). A nivel interno, algunas organizaciones de la sociedad civil comenzaron a escrutar estos primeros pasos, y un cierto nivel de conciencia ambiental empezó a surgir, aunque con lentitud, entre los ciudadanos y los medios de comunicación (Estenssoro, 2009). 
Así las cosas y a diferencia de otros países —en particular de Europa Occidental, donde existe una mayor tradición en este campo-, la política ambiental chilena era ( $\mathrm{y}$ tal vez lo siga siendo) de naturaleza esencialmente reactiva y de actuación ex post (Villarroel \& Erlwein, 2007; Pelfini, 2013). Por lo tanto, no contribuye a la formación de agenda pública, sino que interviene para asesorar, justificar o mitigar los efectos indeseados de agendas preestablecidas relacionadas con proyectos de inversión productivos o extractivos (Rojas et al., 2003).

Si bien, a mediados de los noventa, con esta primera fase comienza a tomar forma la institucionalidad ambiental chilena, no es sino hasta la resolución de procesos y conflictos ambientales ocurridos entre 2005 y 2008, como la crisis de la salmonicultura en el Pacífico Sur de 2007/2008 por el brote del virus ISA, que aparece un cambio profundo en la gestión e institucionalidad ambiental del país (CAPP, 2010). En breve: el brote ISA se refiere a la detección de este virus en salmones producidos en la regiones de Los Lagos, Aysén y Magallanes (Carreño, 2010). Ello generó una crisis socioambiental con múltiples efectos negativos, sobre todo porque el salmón es uno de los principales productos de exportación de la economía chilena. Ante esta situación y la urgencia de fortalecer la institucionalidad ambiental en el país, en 2007 y como parte del proceso de institucionalización de la gestión ambiental, la conama pasó a tener rango ministerial (CAPP, 2013).

De este modo, la segunda fase de la institucionalización de la política ambiental en Chile comenzó con la creación de un Ministerio de Medio Ambiente en 2009, acompañado por un corpus legal más profundo y variado en la materia. La Ley No $20.417^{6}$ creó dicho ministerio (con potestad para diseńar y aplicar políticas, planes y programas ambientales), además del Servicio de Evaluación Ambiental (SEIA), que administra el Sistema de Evaluación de Impacto Ambiental, y la Superintendencia del Medio Ambiente (sMA) (con potestades fiscalizadoras y sancionatorias en materia ambiental) (вСN, 2010a). Asimismo, la ley regula con mayor fuerza la participación ciudadana y el efecto acumulativo o sinérgico de los planes y proyectos a través de la Evaluación Ambiental Estratégica, lo cual pretende, entre otros aspectos, limitar el fraccionamiento de los proyectos (CAPp, 2013). Esta ley, que modifica e introduce nuevas disposiciones en la Ley 19.300, se vincula con la No $20.600^{7}$ que crea los Tribunales Ambientales, órganos jurisdiccionales especiales cuya función es resolver las controversias medioambientales de su competencia y ocuparse de los demás

6 Publicada en el Diario Oficial con fecha de 26 de enero de 2010.

7 Publicada en el Diario Oficial con fecha del 28 de junio de 2012. 
asuntos que la ley somete a su conocimiento. ${ }^{8}$ En resumen, las modificaciones indicadas diferenciaron las funciones de gestión y administración (SEIA), diseño de las políticas (Ministerio), y fiscalización y regulación (Superintendencia), con lo que principió la Nueva Institucionalidad Ambiental del país (NIA), cuyo diseño buscó la transversalidad y coordinación interinstitucional de la temática ambiental (Barton et al., 2007).

Más aún, con la NIA se introdujo una variante novedosa del discurso de modernización ecológica en el gobierno de Michelle Bachelet, la cual integró estándares neoinstitucionalistas de segunda generación de reforma del Estado y de formulación de políticas: después de una ola de privatizaciones, descentralización y desregulación propicia a los mercados (producto de la instauración de un modelo neoliberal en Chile durante el Régimen Militar entre 1973 y 1990) (Valdivia, 2001), hubo una tímida tendencia a desarrollar instituciones más abiertas a la ciudadanía, en respuesta a las demandas por mayor democratización y justicia social. Una mayor "democratización" del Estado (y de los mercados) consistiría, pues, en la incorporación de tres criterios al diseño de instituciones, criterios ampliamente aceptados como quintaesencia de cualquier agenda de democratización y legitimación: accountability o rendición de cuentas - la obligación de los funcionarios de responder por su actos y de ser sancionados por el incumplimiento de sus deberes y compromisos (Cendon, 2000; Peruzzotti \& Smulovitz, 2002; Newell, 2008)—; transparencia —que todos "tengan vista" de lo que ocurre al interior del Estado (Rodríguez, 2004)—; y participación ciudadana. Por lo tanto, la NIA pretende, en relación al primer criterio: i) concentrar responsabilidades respecto de la fragmentación patente en el modelo anterior que diluía competencias y decisiones entre diversos agentes de otros ministerios; ii) volver más transparentes e identificables a los tomadores de decisión y de implementación de normativas y regulaciones ambientales, iii) e incorporar mecanismos participativos en diversas fases de la implementación y evaluación de los proyectos con impacto ambiental.

Igualmente, introduce con timidez algunos criterios vinculados a la idea de justicia ambiental (tratamiento equitativo en cuanto a la distribución de las cargas y beneficios ambientales, y participación significativa en las decisiones correspondientes) como complementos de la sustentabilidad (Hervé, 2010). El problema principal es que buena parte de sus potenciales aportes están con-

8 Se crean tres Tribunales Ambientales, en tres comunas distintas: Antofagasta, Santiago y Valdivia. Los Tribunales Ambientales serán competentes, entre otras materias, para conocer las reclamaciones contra los decretos supremos que establezcan normas primarias o secundarias de calidad ambiental, normas de emisión, los que declaren zonas del territorio como latentes o saturadas, y los que establezcan planes de prevención o de descontaminación. 
tenidos en iniciativas y propuestas que todavía no están claramente reguladas, como es la Evaluación Ambiental Estratégica (EAE) que evaluaría integralmente proyectos individuales en áreas más extensas.

Del modo descrito, la segunda y actual fase de la política ambiental chilena queda marcada por la implementación de la NiA y sus criterios de accountability, transparencia y participación, las cuales se revisarán enseguida con mayor detalle.

\section{La NIA en funcionamiento y la aplicación de la accountability, la transparencia y la participación}

Evaluar el diseño e implementación de la NIA en términos de las reformas de segunda generación y una mayor democratización, supuestamente en contra del reforzamiento de sus redes informales tradicionales, supone detenerse en el análisis de sus tres estándares de gobernanza fundamentales: accountability, transparencia y participación. Analizar estos estándares requiere preguntarse por las continuidades y rupturas de la reforma, por sus actores principales y cómo se vinculan entre ellos, y el entorno en que estas reformas y actores se desenvuelven. En este sentido, en adelante se distingue entre problemas estructurales, limitaciones de contexto y otras restricciones específicas a la NIA y a su diseño e implementación.

Para realizar lo anterior, a diferencia del extendido y más tradicional análisis de legislación, aquí se utilizó una metodología mixta que combina: a) análisis en profundidad de bibliografía y documentos oficiales sobre la NIA en Chile; b) estudios de casos emblemáticos en proyectos energéticos, tanto por su impacto social y mediático como por el tratamiento que se les dio en el marco de la NIA, por ejemplo, el inicio de la construcción de una represa hidroeléctrica en el Alto Maipo o las centrales termoeléctricas de Castilla y Ventanas (Araya, 2013; Asdasme, 2013; Ilabaca, 2013; Rojas, 2013), y c) entrevistas en profundidad, grupos focales y mesas de paneles de expertos, en las que se convocó a actores relevantes y diversos buscando variedad regional. Por ello se realizaron tres paneles de expertos (Santiago, Coihaique, Puerto Montt) entre marzo y mayo de 2013. En las entrevistas grupales participaron unas ocho personas comprendiendo un periodo promedio de 75 minutos, y en todos los casos fueron moderadas por un investigador del equipo estable del proyecto FONDECYT. ${ }^{9}$

9 Cada uno de los informados fue convocado formalmente a participar de las entrevistas mediante una invitación en la que se exponían, en términos generales, los objetivos del estudio. Por su parte, todo los que participaron de las entrevistas han declarado estar al tanto de los propósitos de la investigación y han firmado un consentimiento. En relación a la técnica de análisis para el estudio del corpus de datos, esta 
En políticas públicas suelen aparecer asociadas la noción de transparencia y rendición de cuentas (accountability), responsabilidad, probidad, derecho y acceso a la información. Si bien estas pueden tener elementos en común, cada una tiene su propia trayectoria y función. Aunque no con ese término, el concepto de transparencia ha sido trabajado desde hace siglos; ya desde los romanos y en el medioevo se reflexionaba en torno a la noción de lo que debe o no ser mostrado-revelado públicamente (Rodríguez, 2004). Transparencia se asocia al proceso en que una organización, grupo o persona muestra o presenta información relevante de manera pública sin que haya necesariamente su requerimiento formal. Aquí se hace central la noción de voluntariedad en la mayoría de los casos y el entregar información no solo como respuesta a una demanda, sino de modo constante (Cendon, 2000; Rodríguez, 2004; Transparency International, 2011). Accountability es un concepto amplio que se entiende como accountability política, administrativa, profesional y democrática, y que comparte entre todas sus acepciones la obligación de informar y rendir cuentas sobre los aspectos legales, económicos, administrativos y de probidad de toda política y acción pública (Cendon, 2000; Lindberg, 2013).

Transparencia, asociada a procesos como accountability, junto con ser una de las principales demandas de los stakeholders y de la ciudadanía sobre la operatividad de las políticas públicas, reduciría las asimetrías entre los actores activos de las políticas públicas. En relación a la pregunta central de este artículo, a nivel de las prácticas estos términos juegan un rol central, toda vez que marcan la frontera entre los actos formales y procedimentales y las redes de informalidad no transparentada y los procedimientos que no deben ser rendidos, pero no por eso son ilegales ni pierden trascendencia en la funcionalidad de toda política pública.

En relación a la NIA, la asignación de funciones específicas a tres instancias fundamentales (Ministerio, SEIA y SMA) distribuyéndoles atribuciones admi-

ha combinado principios del análisis de contenido cualitativo y de la vertiente de codificación abierta que propone la teoría fundamentada; así, la revisión de los textos se ha desarrollado sin pautas de codificación preestablecidas, un criterio que permitió salvaguardar aspectos de calidad en la lectura de los datos, pues no busca elementos específicos, sino que da cabida, en todo momento, a lo emergente que pudiese surgir desde entre las personas participantes de las entrevistas. Por su parte, en términos de herramientas de apoyo para la lectura de los datos, el corpus de textos ha sido procesado y fragmentado a través del Atlas-ti 6.2, lo que ha permitido levantar un conjunto de categorías emergentes que, posteriormente, han sido reagrupadas para su análisis en función de las preguntas que orientan el desarrollo del informe (Andrade, 2013). 
nistrativas de evaluación y de fiscalización, respectivamente, en principio, representa una innegable mejora en términos de accountability horizontal, como bien indica un grupo de expertos:

[La NIA] ... se propone mejorar la fiscalización, por eso se crea una entidad específica en materias ambientales de fiscalización, se propone también revisar las controversias y fallar en torno a ellas, las controversias que puede tener un titular, un proyecto, las controversias que puede tener, no es cierto, la comunidad afectada o particulares que se sientan afectados a través de los Tribunales Ambientales y se crea un organismo especializado en materia de evaluación ambiental como es el SEIA. (Grupo de discusión 3c, párrafo 21).

De este modo se mantiene, cuando no se profundiza, la fragmentación de la política ambiental como una cuestión específica y relevante primordialmente para la instancia de injerencia directa en las diversas áreas de gobierno. Buena parte de la política pública queda reducida al instrumento por excelencia de este modelo, que es la evaluación de impacto ambiental por proyecto. Si bien se habla de evaluación estratégica la misma requeriría no solo tener en cuenta varios proyectos confluyentes en un ecosistema determinado, sino también la incorporación de mayor número de actores así como de otras áreas de política para las que la cuestión ambiental es transversal, como la energía y la agrícola (Espinoza, 2007). Un actor que suele quedar al margen de estos procesos son las universidades. Estas instituciones reciben financiamiento en $\mathrm{I}+\mathrm{D}$ para volcarla en patentes e innovaciones útiles para la empresa privada, pero apenas para cuestiones de interés público y de organización de la sociedad civil. Más aún, las mismas universidades podrían intervenir en las evaluaciones ambientales alterando en cierto modo la estrecha y poco transparente ligazón entre consultoras y empresas: "Un tema clave es la independencia de la consultora, eso que la evaluación no sea pagada por la empresa que hace el proyecto, es un chiste, hay que cambiarlo de alguna forma. Es la esencia de todos los males de los proyectos" (Grupo de discusión 3a, párrafo 60).

Esta visión más integrativa de distintos sectores y con un enfoque multidisciplinario sin duda aumentaría la transparencia y accountability de la política ambiental, haciéndola más transversal que la mera publicación de información y los mecanismos formales de participación ciudadana (Harding, Hendriks \& Faruqi, 2009; Fredman, 2012). Sin embargo, el modelo actual que cuenta con una variedad baja de actores no es modificado con la NIA, por lo cual se mantienen las mismas redes formales e informales que tradicionalmente han conectado inversores, Estado y expertos, siendo estos últimos, en general, consultoras que prestan servicios a las empresas inversionistas. 
Teniendo en cuenta la evaluación de las políticas, esto es, la base de la rendición de cuentas, es fundamental incorporar otros criterios cuando esta evaluación procede para la gestión ambiental y en especial para su principal herramienta, el SEIA; al menos según los parámetros del desarrollo sustentable y sus dimensiones ambiental, social y económica, pero siempre superando lo meramente cuantitativo y de rendimiento. Con la NIA al parecer el problema no queda del todo resuelto, ya que como expresan algunos expertos: "El SEIA se autoevaluaba en términos de proyectos aprobados y millones de dólares de proyectos aprobados. Entonces, no es moneda ambiental, no se evalúa en moneda ambiental" (Grupo de discusión 3a, párrafo 62).

De igual modo, un déficit notorio en términos de transparencia es que no existe un listado público de consultoras del que se seleccione aleatoriamente a la que debe evaluar un proyecto específico. En países como Estonia, esas consultoras se encuentran certificadas y son evaluadas con participación ciudadana: "Aquí la empresa escoge la consultora y hace un acuerdo extrañísimo, en una relación no transparente entre la consultora y la empresa" (Grupo de discusión 3a, párrafo 29).

Lo anterior debe también leerse en función de los arreglos institucionales y cómo los principios de transparencia y accountability se validan como mecanismos que permiten consolidar redes informales que conectan a los actores principales de la política ambiental en Chile: los inversores, el Estado (como habilitador) y los expertos (think tanks o consultoras). En este sentido, la NIA si bien mejora y profundiza la forma en que ambos principios funcionan logrando dar mayor validación a los procesos, al no modificar y ampliar su rango de acción, termina revalidando las interacciones y redes informales que históricamente han operado en la gestión y política ambiental chilena.

\section{Participación ciudadana en la NIA}

En términos generales, la incorporación de exigencias de participación ciudadana en la NIA se evalúa positivamente debido a que puede contribuir a mejorar los proyectos de inversión en cuanto a sus beneficios sociales allegando necesidades locales muchas veces ignoradas por los que gestaron un emprendimiento en particular. Si bien la cuestión clave que se debe analizar es la aplicación concreta de la exigencia de incorporar la participación ciudadana en determinadas fases de una EIA, así como las condiciones estructurales que facilitan o dificultan una participación efectiva.

Otro punto central en cuanto a la participación y las restricciones de esta es la frontera entre saber experto y lego (o no profesional, no técnico). En la 
medida en que esta frontera se vuelve infranqueable y los mecanismos participativos se incorporan para cumplir con una especie de checklist, estos ya no se evalúan a la luz de la justicia participativa y solo estimulan la participación en forma genérica, dejando de lado la que vela por la paridad participativa (Fraser, 2007). En este sentido, son cruciales las asimetrías de información entre las partes involucradas (más crucial cuando se considera a las generaciones futuras, tal como debe ser al pensar en términos de sustentabilidad). Si los supuestos mecanismos participativos no reducen las asimetrías de información se convierten en una ficción; bien intencionada, pero ficción al fin. Por lo tanto, se debe prestar especial atención al lenguaje que impera en los informes, justificaciones, dictámenes y en la formulación de programas y en la extensión de estos. Sin embargo, la evidencia parece ir a contramano de esta necesidad niveladora propia de un Estado:

Recuerdo que en el programa de gobierno de Michelle Bachelet se propuso la idea de incorporar como derecho la asesoría técnica de comunidades locales que enfrentaban proyectos, pero quedó ahí, no pasó nada. Entonces resulta que las comunidades están obligadas a hacer observaciones en 120 días sin nada. Si tienen plata se organizan, sino tienen plata, nada. Y en 120 días no son nada para un proyecto que probablemente tardó un año en hacerse... La participación ciudadana es sobre las base de las manos vacías. (Grupo de discusión 3a, párrafo 29).

¡Cuál es la capacidad técnica para enfrentar estos estudios que son digamos la verdad ante Dios! Digamos... y que son estudios de un alto nivel de complejidad técnica y, además, muy caros de obtener. Entonces yo creo que ese es un tema bien clave para poder democratizar las decisiones... (Grupo de discusión 3a, párrafo 35).

si las personas siguen en su ignorancia y no se les dan los medios económicos ni la información... es una democratización mentirosa porque sigue siendo dentro de la ignorancia. (Grupo de discusión 3a, párrafo 40).

Del modo descrito, al final los únicos que pueden participar en la gestión pública son aquellos que entienden el lenguaje científico-ambiental y logran operar los mecanismos de participación, es decir, los mismos que históricamente lo han hecho. Se refuerzan así las redes formales e informales existentes, y se reduce la paridad de participación que debería imperar.

Ahora bien, aunque la Ley 19.300 establece plazos para presentar reclamaciones acerca de un proyecto aprobado (observaciones escritas), la clave es promover capacidades en las comunidades y otros stakeholders a fin de que 
consigan elaborar reclamos consistentes, lo cual supone el desafío de las capacidades y conocimiento de la sociedad civil para entender los proyectos y poder observarlos (Agrawal, 2005; Harding et al., 2009). Si el Estado no se ocupa o promueve el capacity building entre los agentes afectados, los mecanismos participativos pierden potencialidad (UNEP, 2002). Capacity building, entendida como la construcción de capacidades, relaciones y valores que permitan a organizaciones, grupos e individuos mejorar su actuar y rendimiento frente a la temática ambiental, es un importante paso para ampliar las redes existentes en la gestión de la política pública.

Otro elemento a considerar es el carácter vinculante de la participación. Si bien no abundan casos de este tipo a nivel internacional es necesario pasar de lo consultivo a alguna clase de mandato, sobre todo pensando en la sustentabilidad de los mismos proyectos y políticas. Hasta el momento las observaciones escritas solo son útiles para ser ponderadas dentro de una resolución ejecutiva, pero no para rechazar un proyecto (Spoerer, 2013). Si las observaciones fueran vinculantes a la resolución muchos proyectos no serían aprobados o se verían obligados a modificar aspectos claves para funcionar, sin embargo, dado el diseño institucional del SEIA, en la actualidad es muy difícil que un proyecto no logre su aprobación ambiental, independientemente del tiempo que eso tome (Rivera, 2010; Navarro \& Rivera, 2013).

En síntesis, los mecanismos formales de la participación están a la mano, pero apenas hay condiciones para utilizarlos en términos de justicia participativa. Cabe también preguntarse cuánto de esta apertura a la participación es inherente a la institucionalidad ambiental o responde a la confluencia de instrumentos exteriores a la NIA como, por dar varios casos, el Convenio 169 de la OIT en relación a las consultas y autodeterminación de los pueblos indígenas, la ley de acceso a la información, y la Ley 20.500 de participación ciudadana, sobre todo a nivel municipal. Más bien pareciera que la democracia participativa como parte de la política ambiental institucionalizada y oficial queda presa del llamado "pluralismo limitado" (Spoerer, 2013). Asimismo, como presentan Pizarro (2006) y Rivera (2011), es limitada la capacidad de algunos grupos, sobre todo comunidades locales, de disponer sus agendas por sobre las de los inversores privados, principalmente cuando estos logran que el Estado, mediante sus agencias reguladoras, proteja los intereses privados o inclusive convenzan de que su interés — vía el discurso del desarrollo y crecimiento- se convierta en el interés común y público.

En estos términos y en los ya revisados se denota la asimetría entre los procesos participativos, lo cual en parte fortalece los vínculos y participación de los privados, su control sobre el territorio y reduce la capacidad de otros actores de ingresar a las redes formales e informales de la gestión ambiental de Chile. 
Pero más allá del diseńo institucional y la implementación concreta de la NIA, esta se inscribe en una tradición particular de política ambiental en el país y en un marco determinado de interrelación entre actores, y de subordinación a un modelo productivo en especial. Esta mezcla de despolitización, actores corporativos y extractivismo restringe las potencialidades reformistas y democratizantes que esa Nia podría contener. De ahí que se mantengan, e incluso se profundicen, las características ya notorias del marco antecedente. $\mathrm{Y}$ es bajo aquellas que operan los tres estándares de gobernanza estudiados, por lo que es necesario revisar hasta qué punto la NIA no cumple con sus pretensiones originales debido a su diseño, lo que es producto de las características referidas que la constriñen. Este análisis se presenta en los incisos que siguen.

a) Centralidad de los proyectos: La "unidad de análisis" u objeto fundamental de la política ambiental son, sin duda, los proyectos. Estos son el impulsor de las decisiones, el objeto de los controles y regulaciones, y el eje de la controversia pública posterior si el problema en cuestión trasciende los canales institucionales previstos. La política ambiental chilena se desenvuelve más bien en una escala "meso": no existe una planificación general o regional relevante respecto a explotación y protección de recursos, ni tampoco - - a nivel micro - los agentes públicos locales tienen injerencia en lineamientos de política. En este sentido, las políticas públicas se fragmentan desde los proyectos, pero permanecen centralizadas en sus lineamientos generales, procesos de toma de decisión y de evaluación: "Esta institucionalidad ambiental le pegó una maquillada nomás a los niveles locales. Fue una gran reforma a nivel nacional, pero a nivel local fue un maquillaje... Creo que el nivel local pudiese ser una tremenda herramienta para potenciar gestión integrada, la planificación (por ejemplo, con comités de cuenca)" (Grupo de discusión 3a, párrafo 43).

Además de su condición meso, la política ambiental presenta un centralismo político que dificulta la toma de decisiones y resolución de conflictos a nivel local o regional, priorizando por sobre ellas el consenso generado en las cúpulas del poder económico y político del país que consiste en anteponer los objetivos de crecimiento económico por encima de los ambientales (Rojas et al., 2003). Relacionado con la participación, la focalización en los proyectos también es un modo de sesgarla o de reducirla a fases específicas y a asuntos precisos y determinados previamente por los interesados en la aprobación de una inversión o emprendimiento productivo: 
A la gente se le pregunta sobre el proyecto, pero nunca se le pregunta previamente qué usos le da al ecosistema... y a lo mejor la pregunta es guiada [hacia] la participación ciudadana; en vez de preguntar a la gente sino hay una planta, para qué uso el ecosistema. En cambio, cuando tú le preguntas "le impacta la planta", ya estás sesgando que te responda sobre la planta (Grupo de discusión 3a, párrafo 54).

En otros términos, al reducir la participación a proyectos específicos, se niega las posibilidades de leer las pretensiones amplias desde la ciudadanía sobre el uso y conservación del territorio local y nacional, y de planificar y desarrollar una agenda pública en torno a modelos de desarrollo y de uso de recursos naturales (Pelfini, 2013). Para estos fines de mayor planificación y decisión política estratégica existe, según la NIA, la Evaluación Ambiental Estratégica, sin embargo, esta aplica solo en los planes de ordenamiento territorial y desarrollo de envergadura ${ }^{10}$ (MMA \& MINVU, 2011). De este modo, sigue aún vigente el análisis levantado en los noventa por Del Fávero \& Katz (1996), en el que se indicaba que el principal obstáculo para optimizar las bondades de la EAE en Chile era político, un juicio que se basaba en la observación de la falta de transparencia y de participación ciudadana ampliada.

b) Sectorialización: Varias cuestiones de relevancia ambiental se distribuyen y debilitan en una serie de campos de política que son en general tratados sectorialmente y, en términos de políticas públicas, por la instancia de jurisdicción directa (el Ministerio de Minería para la industria minera, Energía para termoeléctricas y represas hidroeléctricas, Agricultura y Pesca para salmonicultura), instancia en la que la política ambiental interviene solo tangencialmente, sobre todo ante crisis o conflictos socioambientales emergentes. Sectorizar e individualizar la política ambiental a la escala del proyecto difumina sus implicancias más globales y sus externalidades que exceden la medición precisa de niveles de contaminación en un área de influencia directa, así como de la estimación de la capacidad regenerativa de un recurso y de su entorno inmediato. De este modo, cuestiones como la presión que se ejerce sobre el uso de la tierra por parte de la industria forestal o por los recursos hídricos (particularmente escasos en las regiones de mayor expansión de emprendimientos mineros) de parte de la indus-

10 En específico, planes regionales de ordenamiento territorial, reguladores comunales, seccionales, reguladores intercomunales, regionales de desarrollo urbano y zonificaciones del borde costero, del territorio marítimo y el manejo integrado de cuencas o los instrumentos de ordenamiento territorial que los remplacen o sistematicen (MMA \& MINVU, 2011). 
tria minera quedan fuera del foco de las EIA. A su vez, la no existencia de una mirada integral respecto a lo que se quiere desarrollar y proteger como país o de una idea que existen bienes colectivos puede ser leída como una interferencia:

Yo creo que también va, un poco de fondo a que no se tiende a ver el sistema y la planificación, o sea, se tiende a pensar que la planificación y entender que algo común — como usamos todos este bien común—, se tiende a pensar que tú estás por coartar la libertad particular, entonces el que te digan que yo tengo mi derecho a hacer lo que quiera en mi terreno porque es mío, y que yo puedo poner donde quiera mi represa porque yo compré los recursos del agua y la cuestión, eh, no poh Señor, existe un suprabien, un bien que va más allá de todo que es la comunidad, el medio ambiente en general, el agua que es de todos, de los parceleros, entonces, ¿sabe qué?, me parece espectacular necesitamos luz para el norte, pero aquí no, ¿sabe qué? hágala en otro lado, aquí ya no es lo más apto para eso, y eso no se puede [hacer] porque estoy atropellando (Grupo de discusión 3b, párrafo 37).

c) Judicialización: En primera instancia, la judicialización tiende a verse como negativa per se, o como una forma de profundizar la tendencia a la despolitización. Sin embargo, por el modo en que se desarrolló en Chile, la judicialización aparece como una estrategia por default que se origina en agentes con menos peso político debido al autismo de las instancias tomadoras de decisiones (ejecutiva y legislativa). Los recursos de protección o recursos cautelares suelen ser presentados por parte de comunidades y ONG a fin de no innovar o exigir mayor información y regulación a los proyectos de inversión. Por lo mismo, las resoluciones de la Corte Suprema tienen un gran impacto en la opinión pública puesto que se trata, en general, de resoluciones rápidas, notorias y que plantean sanciones concretas. Judicializar o rejudicializar la problemática socioambiental presionando a la Corte Suprema sería, paradójicamente, un intento de repolitizar la cuestión o de al menos salir del corsé de la NIA. Podría concluirse entonces que mientras el Poder Ejecutivo parece cercado por una troika inversores-Estado-expertos, el Poder Judicial sería algo más independiente y abierto al escrutinio público mostrándose como un ámbito válido para una discusión social más amplia. Todo esto permite comprender por qué, junto a la NIA, los sectores denominados "proproyectos" promovieron la creación de los Tribunales Ambientales como sustituto de los tribunales ordinarios (Del Real, 2013). Es más, la misma creación de los Tribunales Ambientales puede considerarse como un avance en la despolitización que 
se había iniciado con la Ley 19.300 y el pasaje de lo exigible a lo deseable, así como del derecho a vivir en un ambiente no contaminado y el deber de aportar a no contaminarlo o a descontaminarlo. Los Tribunales Ambientales requieren de un saber específico tanto para las partes litigantes como para los mismos abogados que los representan; cabe acotar que no es el mismo tipo de saber y de competencias requeridos en los tribunales ordinarios.

d) Hegemonía de los privados: Así como el proyecto de inversión es el objeto por excelencia alrededor del cual gira la NIA, el sujeto de esta no parece ser el Estado ni la ciudadanía sino la figura abstracta del "titular del proyecto". Esta figura es la que genera el input, cumple con ciertas exigencias y procedimientos y termina por originar el output deseable que no es más que un proyecto de explotación de recursos naturales, pero ambientalmente "sustentable". Dentro del espíritu de la gobernanza privada, el Estado se limita entonces a un rol fiscalizador:

Hoy día lo que tenemos es una mejor fiscalización, ¿por qué?, porque básicamente hay más plata, pero cuando vamos a la planificación, y yo creo que si hay un consenso de los que estamos acá es que necesitamos un mayor nivel de ordenamiento. O sea, esto de que cualquier gallo para el día de hoy vaya a decir voy a hacer algo acá, y trate de pasar como mejor pueda esta línea sobre el abismo que es la evaluación ambiental pa' llegar al otro lado y recibir un chancacazo con un tribunal que le saca una orden de renovar, y es insostenible para todos. Es insostenible para el Estado, porque yo hoy día estoy en la parte que tengo es insostenible para inversionistas que quiere hacer un proyecto e insostenible para la comunidad dónde surge ese proyecto, donde se ejecuta, o sea algo tenemos que hacer. (Grupo de discusión 3a, párrafo 43).

Adicionalmente, una cuestión fundamental que se soslaya cuando se focaliza en una política pública específica olvidando el marco en que se inserta, es que no hay lugar para los derechos y atribuciones de determinados agentes, cuando esto debería anteponerse a la intervención de una política ambiental determinada. Esto es fundamental para entender la asimetría entre actores que se evidencia con la hegemonía de los privados: la existencia de derechos de propiedad sobre bienes que por definición son o debieran ser públicos (el caso sobresaliente en Chile es el agua, que es de régimen privado). En un caso muy destacado, el del Proyecto Hidroeléctrico Alto Maipo, Adasme (2013) muestra cómo la cuestión de los derechos de agua constituye un límite estructural a cualquier política ambiental aun cuando 
esta se plantee con las más estrictas exigencias de accountability, transparencia y participación ciudadana. ${ }^{11}$

Para concluir este análisis sobre el funcionamiento de la NIA, se debe decir que el problema central no es entonces exclusivo de su diseño, sino más bien de sus limitaciones para alterar un marco restringido, controlado y orientado casi ex profeso al éxito de proyectos de inversión. Es más, por parte de los entrevistados y según la literatura revisada, la NIA ha sido evaluada positivamente como un avance respecto del laxo marco previo de política ambiental que, desde los noventa y hasta la formación de un Ministerio en 2009, se limitaba a generar coordinación en temáticas de gestión ambiental, pero no diseñaba ni gestionaba políticas propias (Barton et al., 2007; Ilabaca, 2013). Esto se destaca sobre todo entre los representantes de regiones donde agentes públicos y privados parecen converger con mayor proximidad en la defensa, y explotación a la vez, de ciertos recursos que traen beneficios directos a la población local como el notorio caso de la salmonicultura: "yo estimo que habrá habido un beneficio para efectos de la sustentabilidad ambiental, ya que también la ley introdujo los elementos de evaluación, es un avance, es un avance obviamente en función también del titular del proyecto, no solamente la salmonicultura. Claramente es un avance positivo" (Grupos de discusión 3c, párrafo 11).

Al reducirse la política ambiental a una cuestión tecno-científica susceptible de ser tratada aisladamente (centralidad de los proyectos y por sectores) y solo por expertos, se restringe al mismo tiempo el número y tipo de actores susceptibles de intervenir legítimamente en tal política, lo que profundiza el neocorporativismo y la oligarquización existentes. De este modo, se reduce la cuestión ambiental a la gestión (en su mayor parte, privada), sustrayéndola del debate público sobre modelos de desarrollo de largo plazo donde intervendrían valores plurales, saberes diversos e intereses contrapuestos. Los esfuerzos en esta dirección se han realizado introduciendo y afinando exigencias de accountability, transparencia y participación, pero siempre en el marco existente de gobernanza privada: los gobiernos nacionales y regionales publican informes; las empresas desarrollan proyectos de desarrollo social en beneficio de las comunidades locales, y ningún proyecto

11 La coordinadora del movimiento ciudadano Ríos del Maipo alega que en conversaciones con la empresa AES Gener, titular del proyecto, una representante ratificó la primacía y autonomía de los intereses privados respecto de cualquier regulación ambiental: "Tal como dijo Patricia Alvarado en una reunión con vecinos: 'bueno, y por último, los derechos de agua son de nosotros y el negocio es nuestro'. Es cierto que el negocio es de ellos, entonces ellos cuentan con esa impunidad, la conocen, lo saben, la usan. Entonces el modelo está hecho para que ellos sigan adelante con su negocio." (Entrevista a Marcela Mella en Adasme, 2013). 
de inversión con un impacto ambiental significativo es aprobado sin algún grado de participación de los directamente afectados. Quiénes son esos pocos privilegiados que pueden intervenir en la política ambiental, cuyas consecuencias de gravedad son tanto para el conjunto como para futuras generaciones, es lo que abordamos en las siguientes páginas de cierre.

\section{Conclusiones: oligarquización e instrumentalización de las instituciones}

Como se demuestra en el análisis anterior, en el marco de la gobernanza privada, la política ambiental en Chile, aun en su fase actual de mayor institucionalización, se dedica primordialmente a reproducir y legitimar un modelo de desarrollo: acumulación basada en la extracción y exportación de materias primas, lo que constituye la base de la relativa riqueza actual del país. La salmonicultura, la madera y los minerales representan los principales productos de exportación chilenos, y han sido objeto de regulación ambiental con tres objetivos principales: la preservación del recurso, pero no del ecosistema circundante; el control de conflictos socioambientales, pero no la salvaguarda de los intereses de los afectados actuales y potenciales, y el resguardo de la "seguridad jurídica” y del interés de los inversionistas. Esto se plasma sin mayores resquemores en la llamada doctrina Frei que, elaborada luego de la Ley 19.300 y esbozada informalmente hacia 1996, estructura la política ambiental durante los gobiernos de la Concertación y representa una deliberada subordinación de las exigencias de sustentabilidad y regulación ambiental a los imperativos de un modelo económico extractivista orientado a la exportación de materias primas. La doctrina Frei puede resumirse en las siguientes consignas: "Ninguna inversión debe detenerse por motivos ambientales"; "Los funcionarios no rechazan proyectos; sino que los aprueban con condiciones" (Larraín, 2006).

En esta delimitación y reducción de la política ambiental a la estimación técnico-científica de los efectos ambientales directos - "las condiciones para poder aprobar proyecto", en palabras de la doctrina Frei- de proyectos de inversión intervienen al menos tres actores centrales: $a$ ) el inversor (usualmente capitales transnacionales), llamado de modo genérico en la NIA "titular del proyecto"; b) el Estado como instancia habilitadora que autoriza y regula el proyecto de inversión, y c) los expertos (think tanks o agencias de evaluación de impacto ambiental), que proporcionan legitimidad científica al proyecto en cuestión. ${ }^{12}$

12 El triángulo o troika entre Política (reducida a gerenciamiento de políticas públicas), Empresa (orientada al crecimiento y a la innovación por destrucción creativa) y Ciencia (que ofrece un conocimiento 
De esta forma, actores conectados a través de sólidas redes intraélite —cuando no neocorporativistas, como lo dice Aguilar (1989)_ dominan el campo de las políticas ambientales, mientras que la sociedad civil y la ciudadanía en su conjunto quedan relegados al papel de observadores. En otras palabras, lo ambiental queda sometido a redes informales, que reproducen un discurso y prácticas asociadas a un modelo de desarrollo extractivista, consolidándose así la heredada oligarquización de la política y la gestión ambiental en Chile.

No obstante los avances en cuanto a un reforzamiento y formalización de la política ambiental, dentro de la NIA, la hegemonía de la red formada por los inversionistas, el Estado y los expertos, permanece intocada, e incluso reforzada, por esta inyección de legitimidad derivada de las reformas cosméticas descritas. En este sentido, es posible hablar de un proceso de democratización incipiente pero después detenido, precisamente debido a la instrumentalización de criterios en origen concebidos al servicio de la democratización de las instituciones. En esta constelación, los ideales progresistas y democráticos de rendición de cuentas, transparencia y participación se han reducido a un instrumento para la separación de Estado, mercado y la sociedad civil, enfatizando en las asociaciones (partenariados) flexibles y la autorregulación. Ciertamente, se ha iniciado un proceso de aprendizaje colectivo y cierto grado de democratización también ha ocurrido, pero en forma de un proceso "tutelado" - bien conocido en la larga transición chilena—, en el contexto de una democracia de baja intensidad. Oligarquización y extractivismo funcionan así como cerrojos estructurales a estos impulsos democratizadores de la política ambiental. Estos ideales de accountability, transparencia y participación han terminado contribuyendo a consolidar una forma objetivante de administración o ingeniería social en la que los sujetos políticos se difuminan (Crouch, 2004). La pregunta que surge aquí es si estas limitaciones son simple consecuencia de la instrumentalización de ideales democráticos (accountability, transparencia y participación) por parte de una coalición neocorporativista de grupos de élite, o si, por el contrario, radican de alguna forma en estos ideales en sí mismos, y que a fin de cuentas estos fueran menos progresistas y democráticos de lo que habitualmente se considera.

experto que otorga certezas y realiza predicciones a partir de inferencias causales); el sostén de lo que Tironi llama Buenos Viejos Tiempos (вVT): "Lo que está en la base de esa crisis de confianza, que tiene como damnificados tanto a la dupla Democracia/Política como a aquella de Empresa/Capitalismo, es el atascamiento del dispositivo de producción de certidumbre y de obediencia a la autoridad basado en el razonamiento y la verdad científicos con su corolario natural: la autoridad indiscutida de los expertos" (Tironi, 2014: p. 43). 


\section{Referencias}

Agrawal, A. (2005). Environmentality: Community, Intimate Government, and the Making of Environmental Subjects in Kumaon, India. Current Anthropology, 46(2), 161-190.

Aguilar Fernández, S. (1989). Neocorporatismo: origen del debate y principales tendencias. Politica y Sociedad, 3, 57.

Araya, C. (2013). El espacio de acción de la sociedad civil en la Nueva Institución Ambiental. En el caso de la Central Termoeléctrica Castilla. Trabajo final de graduación en Sociología. Santiago, Chile: Universidad Alberto Hurtado.

Asdasme, C. (2013). Canales formales de aprobación en los proyectos energéticos en Chile, una rendición de cuentas predilecta para los privados. Trabajo final de graduación en Sociología. Santiago, Chile: Universidad Alberto Hurtado.

Aylwin, P. (1992). Mensaje Presidencial Ley 19.300 Bases Medioambientales. En Historia de la Ley 19.300 (pp. 4-44). Valparaíso, Chile: Biblioteca del Congreso Nacional de Chile.

Barton, J. R. \& Floysand, A. (2010). The Political Ecology of Chilean Salmon Aquaculture, 1982-2010: A Trajectory from Economic Development to Global Sustainability. Global Environmental Change, 20(4), 14. doi:10.1016/j.gloenvcha.2010.04.001

Barton, J., Reyes, F., Galilea, S., Prieto, M. \& Alamos, P. (2007). El nuevo diseño de la institucionalidad ambiental en Chile. En Camino al Bicentenario: Propuestas para Chile (pp. 136-177). Santiago, Chile: Universidad Católica de Chile.

BCN. (2010a). Historia de la Ley $N^{\circ} 20.417$. Valparaíso, Chile: Biblioteca del Congreso Nacional de Chile. Recuperado de www.bcn.cl/obtienearchivo?id=recursoslegales/10221.3/3929/6/ HL20417.pdf

BCN. (2010b). Ley $N^{\circ} 20.417$. Valparaíso, Chile: Biblioteca del Congreso Nacional de Chile. Recuperado de www.bcn.cl/obtienearchivo?id=recursoslegales/10221.3/3929/6/HL20417 .pdf

BCN. (1994). Historia de la Ley No 19.300. Bases del Medio Ambiente. Biblioteca del Congreso Nacional de Chile. Recuperado de www.leychile.cl/Navegar/scripts/obtienearchivo?id=recu rsoslegales/1022

Boettiger, C. (2010). Nueva institucionalidad ambiental. Actualidad Jurídica, (22), pp. 429-454.

Bravo, V. (2012). Neoliberalismo, protesta popular y transición en Chile, 1973-1989. Política y Cultura, (37), 85-112. 
Campos, F. \& Larenas, J. (2012). La despolitización del conflicto socio-ecológico en la legislación medioambiental chilena a partir de los años noventa. Bitácora Urbano Territorial, 21(2), 45-56.

Capp (Ed.). (2013). Informe país: Estado del medio ambiente en Chile 2012. Chile: Centro de Análisis de Políticas Públicas (CAPP)/Instituto de Asuntos Públicos/Universidad de Chile.

CAPP (Ed.). (2010). Informe pais: Estado del medio ambiente en Chile 2008: Geo Chile. Chile: Centro de Análisis de Políticas Públicas (CAPP)/Instituto de Asuntos Públicos/Universidad de Chile.

Carreño, A. (2010). Impactos del virus ISA en Chile. ADCE, (55). Recuperado de http://www .terram.cl/2010/01/01/adce_no_55_impactos_del_virus_isa_en_chile_/

Carruthers, D. (2001). Environmental Politics in Chile: Legacies of Dictatorship and Democracy. Third World Quarterly, 22(3), 343-358. doi:10.1080/01436590120061642

Cendon, A. (2000). Accountability and Public Administration: Concepts, Dimension, Developments. En Kelly,M. (Ed.). Openness and Transparency in Governance: Challenges and Opportunities (pp. 22-61). Bratislava, Maastricht: NISPAcee.

Conama. (2010, agosto). Nueva Institucionalidad Ambiental Chilena, algunos ejes estratégicos. Presentación oeCD, Sector Químico. Santiago, Chile. Recuperado de http://www.asiquim. cl/web/documentos/presentaciones\%20Sem_CRespAgosto2010/Presentacion_OECD_ Quimicos.pdf

Conama. (1998). Una politica ambiental para el desarrollo sustentable. Santiago, Chile: Comisión Nacional del Medio Ambiente (CONAMA). Recuperado de http://www.sinia.cl/1292/ articles-26000_pdf_politica.pdf

Crouch, C. (2004). Post-Democracy. Cambridge: Polity.

Del Fávero, G. \& Katz, R. (1996). La Evaluación Ambiental Estratégica (EAE) y su aplicación a políticas, programas y planes. Centro de Estudios Públicos, (64), 95-106.

Del Fávero, G. \& Katz, R. (2001). Gestión ambiental en Chile. En La Transformación Económica de Chile (pp. 247-290). Santiago de Chile: Centro de Estudios Públicos. Recuperado de http://www.cepchile.cl/dms/archivo_3261_1614/07_favero.pdf

Del Real, N. (2013). Paridad participativa en los mecanismos resolutivos del conflicto ambiental: el nuevo escenario propuesto por los Tribunales Ambientales en Chile. Trabajo final de graduación en Sociología. Santiago, Chile: Universidad Alberto Hurtado. 
Escobar, A. (1999). The Invention of Development. Current History, 81(631), 382-386.

Espinoza, G. A. (2007). Gestión y fundamentos de evaluación de impacto ambiental. Santiago, Chile: BID/CED. Recuperado de http://siar.regionpuno.gob.pe/public/docs/1052.pdf

Estenssoro, F. (2009). Medio ambiente e ideología: la discusión pública en Chile, 1992-2002: antecedentes para una historia de las ideas politicas a inicios del siglo XXI. Santiago, Chile: Ariadna Ediciones/Universidad de Santiago de Chile.

Fraser, N. (2007). Transnationalizing the Public Sphere: On the Legitimacy and Efficacy of Public Opinion in a Post-Westphalian World. Theory, Culture \& Society, 24(4), 7-30. doi:10.1177/0263276407080090

Fredman, P. (2012, marzo). Universities as Role Models for Sustainable Development. Presentado en euA Annual Conference "The Sustainability of European Universities". Warwick, UK. Recuperado de http://www.eua.be/Libraries/EUA_Annual_Conf_2012_Warwick/ FINAL_Pam_Fredman.sflb

Gobierno de Chile. (1980). Constitución Política de la República de Chile. Valparaíso, Chile: Editorial Jurídica de Chile.

Harding, R., Hendriks, C. M. \& Faruqi, M. (2009). Environmental Decision-Making: Exploring Complexity and Context, 6th ed. Annandale, Nsw: Federation Press.

Hervé, D. (2010). El Desarrollo Sustentable y la Justicia Ambiental en la Ley 19.300 y en el Proyecto de Reforma. En Guiloff, M., Hervé, D. \& Pérez, R. (Eds.). Reforma a la institucionalidad ambiental: Antecedentes y Fundamentos (pp. 265-288). Santiago, Chile: Universidad Diego Portales.

Hurtado, D. (2012). Cultura tecnológico-política sectorial en contexto semiperiférico: el desarrollo nuclear en la Argentina (1945-1994). Revista Iberoamericana de Ciencia, Tecnología y Sociedad, 7(21), 163-192.

Ilabaca, T. (2013). Nueva Institucionalidad Medio Ambiental y su ensamblaje socio-técnico. Trabajo final de graduación en Sociología. Santiago, Chile: Universidad Alberto Hurtado.

Larraín, S. (2006). Desafíos ambientales del desarrollo nacional. Evaluación desempeño 19972006 y propuesta institucional. En Foco, 96. Recuperado de http://www.expansiva.cl/media/en_foco/documentos/03102006112654.pdf

Lindberg, S. (2013). Mapping Accountability: Core Concept and Subtypes. International Review of Administrative Sciences, 79(2), 202-226. doi:10.1177/0020852313477761 
MMA \& MINVu. (2011). Guía para la Evaluación Ambiental Estratégica. MMA (Ministerio del Medio Ambiente)/Minvu (Ministerio de Vivienda y Urbanismo). Recuperado de http://www. mma.gob.cl/eae/1315/w3-article-50108.html

Navarro, R. \& Rivera, C. (2013). Evaluación ambiental en Chile. Revista del CLAD Reforma y Democracia, 55. Recuperado de: http://old.clad.org/portal/publicaciones-del-clad/revistaclad-reforma-democracia/articulos/055-Febrero-2013/Navarro.pdf

Newell, P. (2008). Civil Society, Corporate Accountability and the Politics of Climate Change. Global Environmental Politics, 8(3), 122-153.

Olivares, A. (2010). El nuevo marco institucional ambiental en Chile. Revista Catalana de Dret Ambiental, 1(1), 15-23.

Pelfini, A. (2013, octubre). Los limites de la gobernanza privada en politica ambiental en Chile. Presentado en Grupo de Trabajo 15: "Medio Ambiente”, ALAs 2013 (xxIx Congreso Latinoamericano de Sociología), Santiago de Chile. Recuperado de http://actacientifica.servicioit. cl/biblioteca/gt/GT15/GT15_PelfiniA.pdf

Peruzzotti, E. \& Smulovitz, C. (Eds.). (2002). Controlando la política: ciudadanos y medios en las nuevas democracias latinoamericanas. Buenos Aires: Temas.

Pizarro, R. (2006). Los cinco problemas de la institucionalidad ambiental en Chile. En Foco, 89, 1-20.

Rivera, C. (2011). Conflictos ambientales y redes transnacionales de defensa en el Chile Postdictadura. Revista de Ciencias Sociales, 17(2). Recuperado de http://200.74.222.178/index .php/rcs/article/view/13807

Rivera, C. (2010). Internacionalización de movimientos sociales. ¿Cuán efectivas son las redes transnacionales de apoyo? Papel Político, 15(2), 617-636.

Robinson, S. (1992). El proyecto Hidroeléctrico Pangue, Río BíoBío, Chile y su importancia para el futuro de las obras de infraestructura. Alteridades, 2(4), 85-91.

Rodríguez Zepeda, J. (2004). Estado y transparencia: un paseo por la filosofia política. México: IFAI. (Cuadernos de Transparencia, núm. 4).

Rojas, A., Sabatini, F. \& Sepúlveda, C. (2003). Conflictos ambientales en Chile: aprendizajes y desafíos. Revista Ambiente y Desarrollo de CIPMA, 12(2), 22-30. 
Rojas, P. (2013). Análisis de la participación ciudadana en Proyecto Hidroeléctrico Alto Maipo, principales avances y desafios hacia la Justicia Participativa. Trabajo final de graduación en Sociología. Santiago, Chile: Universidad Alberto Hurtado.

Rudder, C. (2007). Private Governance as Public Policy: A Paradigmatic Shift. Recuperado de sitemason.vanderbilt.edu/files/hjHBio/Private_Governance_RUDDER.pdf

Soria, C. (2001). Desarrollos de política ambiental en Chile, Ecuador y Perú. En Foy, P. (Ed.). Derecho y ambiente. Nuevas estimativas y proyecciones. Lima: Pontificia Universidad Católica del Perú.

Spoerer, M. (2013). Participación ciudadana e incidencia política: estudio del caso Barracones. Persona y Sociedad, XXVII (1), 17-44.

Terlouw, K. (2003). Semi-Peripheral Developments: From World-Systems to Regions. Capitalism Nature Socialism, 14(4), 71-90. DOI: 10.1080/10455750308565547

Tironi, E. (2014). Apología de la intuición:o cómo comprender el desprestigio de la democracia y la empresa. Santiago de Chile: Ariel.

Transparency International. (2011). Transparency Annual Report 2010. Transparency International. Recuperado de http://www.transparency.org/whatwedo/publication/transparency_ international_annual_report_2010

uneP. (2002). Capacity Building for Sustainable Development: An Overview of UNEP Environmental Capacity Development Activities. Nairobi, Kenya: United Nations Environment Programme (UNEP).

Valdivia Ortiz de Zárate, V. (2001). Estatismo y neoliberalismo: un contrapunto militar Chile 1973-1979. Historia, 34, 167-226.

Villarroel, P. \& Eriwein, A. (2007). Hacia una institucionalidad ambiental de segunda generación para Chile: La necesidad de un enfoque participativo, sinérgico e integrador. Revista Ambiente y Desarrollo de CIPMA, 23(3), 36-42.

Wallerstein, I. (1976). Semi-Peripheral Countries and the Contemporary World Crisis. Theory and Society, 3(4), 461-483.

Recibido el 13 de enero de 2014. Aceptado el 2 de octubre de 2015. 